\title{
CLUSTERING DATA EKSPOR BUAH-BUAHAN BERDASARKAN NEGARA TUJUAN MENGGUNAKAN ALGORITMA K-MEANS
}

\author{
Haviz Atma Negara ${ }^{1}$, Achmad Rizaldi Putra ${ }^{2}$, Ultach Enri ${ }^{3}$ \\ 1,2,3 Teknik Informatika, Fakultas Ilmu Komputer, Universitas Singaperbangsa Karawang, \\ Karawang41361, Indonesia \\ ${ }^{1}$ haviz.atma17109@student.unsika.ac.id, ${ }^{2}$ achmad.rizaldi17033@student.unsika.ac.id, \\ ${ }^{3}$ ultach@staff.unsika.ac.id
}

\begin{abstract}
ABSTRAK
Indonesia merupakan salah satu negara pengekspor ke negara-negara maju dan berkembang. Eksportir bertujuan untuk memperoleh keuntungan demi menunjang perekonomian dan kemakmuran masyarakat. Penelitian ini membahas tentang penerapan data mining pada ekspor buah-buahan menurut negara tujuan menggunakan kmeans clustering method. Data yang digunakan dalam penelitian ini adalah data Ekspor Buah-buahan Menurut Negara Tujuan Utama dari tahun 2012-2019 yang diambil dari dokumen-dokumen keterangan ekspor impor yang dihasilkan oleh Direktorat Jenderal Bea dan Cukai. Data akan diolah dengan melakukan clustering dalam 3 cluster yaitu cluster tingkat ekspor tinggi, cluster tingkat ekspor sedang dan cluster tingkat ekspor rendah. Centroid data untuk cluster tingkat ekspor tinggi sebesar 2054519.3, centroid data untuk cluster tingkat ekspor sedang sebesar 489020.3, centroid data untuk cluster tingkat ekspor rendah sebesar 20.2. Sehingga diperoleh penilaian berdasarkan indeks ekspor buah-buahan dengan 2 negara cluster tingkat ekspor tinggi yakni negara Tiongkok \& Malaysia, 2 negara cluster tingkat ekspor rendah yakni Vietnam \& Thailand, dan 6 negara cluster tingkat ekspor rendah yakni Hongkong, Singapura, Nigeria, India, Jepang, Uni Emirat Arab. Sehingga diperoleh informasi hasil pengelompokan data baru yang dapat menjadi masukan bagi pemerintah maupun perusahaan-perusahaan agar memprioritaskan serta dapat lebih meningkatkan kegiatan ekspor buah-buahan berdasarkan klaster yang telah dilaksanakan.
\end{abstract}

Kata Kunci-Clustering, K-Means, Rapid Miner, Data Mining, Ekspor, Buah-buahan.

\begin{abstract}
Indonesia is one of the exporting countries to developed and developing countries. Exporters aim to obtain profits for the sake of supporting the economy and the prosperity of society. This study discusses the application of data mining to fruit exports according to destination countries using the k-means clustering method. The data used in this research is the data on the export of fruits by main destination countries from 2012-2019 which are taken from the export-import information documents produced by the Directorate General of Customs and Excise. The data will be processed by clustering in 3 clusters, namely the high export level cluster, the medium export level cluster and the low export level cluster. The data centroid for the high export level cluster is 2054519.3, the data centroid for the medium export level cluster is 489020.3, the data centroid for the low export level cluster is 20.2. So that an assessment is obtained based on the fruit export index with 2 high export cluster countries, namely China \& Malaysia, 2 countries with low export level clusters namely Vietnam \& Thailand, and 6 countries with low export level clusters namely Hong Kong, Singapore, Nigeria, India, Japan. , United Arab Emirates. In order to obtain information on the results of new data grouping that can be input for the government and companies to prioritize and be able to further increase the export activities of fruits based on the clusters that have been implemented.
\end{abstract}

Keywords-Clustering, K-Means, Rapid Miner, Data Mining, exports, fruits. 
Jurnal Ilmiah Ilmu Komputer Vol. 7, No. 2, September 2021

Fakultas Ilmu Komputer

Universitas AL Asyariah Mandar

\section{PENDAHULUAN}

Sejak dahulu Indonesia sudah dikenal sebagai salah satu negara agraris, yang artinya sektor pertanian memegang peranan penting dari keseluruhan perekonomian nasional. Hal ini dapat ditunjukkan dari banyaknya penduduk atau tenaga kerja yang hidup atau bekerja dalam sektor pertanian atau dari produk nasional yang berasal dari sektor pertanian.

(Soekartawi, 1999)Pertanian dalam arti luas terdiri dari lima sektor, yaitu tanaman pangan, perkebunan, peternakan, perikanan dan kehutanan. Kelima sektor pertanian tersebut bila ditangani dengan serius sebenarnya akan mampu memberikan sumbangan yang besar bagi perkembangan perekonomian Indonesia mendatang. Salah satu cara penanganannya yaitu dengan berorientasi pada bisnis pertanian atau agrobisnis.[1]

Seiring berjalannya waktu dirasa sangat disayangkan jika Indonesia tidak memanfaatkan hasil alamnya dengan maksimal, demi menunjang perekonomian dan kemakmuran masyarakat ekspor pangan dilakukan untuk mendapatkan keuntungan lebih besar yang bisa dimanfaatkan untuk menunjang pembangunan ekonomi nasional.

(Agus Perdana Windarto., 2017) pada penelitiannya melakukan penilaian terhadap hasil ekspor buah-buahan berdasarkan negara tujuan dengan menerapkan metode clustering K-Means. Data diolah untuk memperolah nilai dari produksi ekspor buahbuahan berdasarkan negara tujuan. Data tersebut diolah menggunakan Rapidminner untuk ditentukan nilai centroid dalam 3 cluster yaitu cluster tingkat ekspor tinggi, cluster tingkat ekspor sedang dan cluster tingkat ekspor rendah. Cetroid data untuk cluster tingkat ekspor tinggi 904.276,5, Cetroid data untuk cluster tingkat ekspor sedang 265.501 dan Cetroid data untuk cluster tingkat ekspor rendah 34.280,1. Sehingga diperoleh penilaian berdasarkan indeks ekspor buahbuahan dengan 2 negara cluster tingkat ekspor tinggi yakni India dan Pakistan, 3 negara cluster tingkat ekspor sedang yakni Singapura, Bangladesh dan Negara lainnya dan 6 negara cluster tingkat ekspor rendah yakni Hongkong, Tiongkok, Malaysia, Nepal, Vietnam dan Iran. Hasil yang dari penelitian dapat digunakan untuk mengetahui jumlah ekspor buahbuahan menurut negara tujuan.[2]

Berdasarkan uraian diatas tujuan dari penelitian ini adalah menerapkan algoritma k-means untuk mengcluster ekspor buah-buahan berdasarkan negara tujuan. Nantinya hasil dari penelitian ini dapat menjadi masukkan kepada pemerintah, negara yang menjadi prioritas tertinggi pada kegiatan ekspor buah-buahan berdasarkan klaster yang telah dilakukan.[3]

\section{TINJAUAN PUSTAKA}

\subsection{Data Mining}

Data Mining merupakan disiplin ilmu yang mempelajari metode untuk mengekstrak pengetahuan atau menemukan pola dari suatu data yang besar. Data
(P) ISSN 2442-451X

(O) ISSN 2503-3832

mining bekerja dengan metode mengolah data terstruktur dengan menggunakan konsep machine learning. Berikut merupakan pendapat beberapa ahli tentang data mining :

[1]Menurut (Witten et al., 2011) Melakukan ekstraksi untuk mendapatkan informasi penting yang sifatnya implisit dan sebelumnya tidak diketahui, dari suatu data.

[2]Menurut (Darmawan et al., 2018) Data Mining adalah suatu proses menemukan hubungan yang berarti, pola, dan kecenderungan dengan memeriksa dalam sekumpulan besar data yang tersimpan dalam penyimpanan dengan menggunakan teknik pengenalan pola seperti teknik statistik dan matematika.

[3]Sedangkan menurut (Han et al., 2011) Ekstraksi pola atau pengetahuan yang menarik (non-trivial, implisit, yang sebelumnya tidak diketahui dan berpotensi berguna dari data dalam jumlah yang besar.

\subsection{K-Means Clustering}

Salah satu metode yang cukup banyak dipakai adalah clustering. Clustering artinya membagi data yang tidak memiliki label menjadi beberapa kelompok.Variabel yang digunakan dalam penelitian ini : jumlah ekspor berat bersih (ton) dan nilai Free On Board (FOB). FOB adalah penyerahan barang yang dilakukan diatas kapal yang selanjutnya akan melakukan pengangkatan barang. Data ekspor buahbuahan Menurut Negara Tujuan Utama dari tahun 2012-2019 akan diolah dengan menggunakan clustering yang dibagi menjadi 3 cluster yaitu cluster tingkat ekspor tinggi, cluster sedang dan cluster rendah.

Pengelompokan data dengan metode K-Means dilakukan dengan algoritma sebagai berikut :

1. Tentukan jumlah kelompok yang akan dibagi.

2. Alokasikan data ke dalam kelompok secara acak pusat kelompok.

3. Hitung (centroid/rata-rata) dari data yang ada di masingmasing kelompok. Lokasi centroid setiap kelompok diambil dari rata-rata (mean) semua nilai data pada setiap fiturnya. Jika M menyatakan jumlah data dalam sebuah kelompok,i menyatakan fitur ke-i dalam sebuah kelompok, dan p menyatakan dimensi untuk data, maka persamaan menghitung centroid fitur ke-i digunakan persamaan.

4. Persamaan 1 dilakukan sebanyak $p$ dimensi dari $i=1$ sampai dengan $i=p$, menggunakan rumus 1 :

$$
C_{i}=\sum_{M}^{1}{ }_{j=1}^{M} x j
$$


Jurnal Ilmiah Ilmu Komputer Vol. 7, No. 2, September 2021

Fakultas Ilmu Komputer

Universitas AL Asyariah Mandar

5. Alokasikan masing-masing data ke centroid/rata-rata terdekat. Ada beberapa cara yang dapat dilakukan untuk mengukur jarak data ke pusat kelompok, diantaranya adalah Euclidean. Pengukuran jarak pada ruang jarak (distance space) Euclidean dapat dicari menggunakan rumus 2 :

$$
d=\sqrt{(x 1-x 2)^{2}+(y 1-y 2)^{2}}
$$

Pengalokasian kembali data ke dalam masing-masing kelompok dalammetode K-Means didasarkan pada perbandingan jarak antara data dengan centroid setiap kelompok yang ada. Data dialokasikan ulang ke kelompok yang memiliki centroid jarak terdekat secara tegas. Pengalokasian data ini menggunakan rumus 3 :

$$
a i l=\left\{\begin{array}{l}
1 \\
0
\end{array} \quad d=\min \{D(x i, c i)\}\right.
$$

Fungsi objektif yang digunakan pada metode K-Means dihitung berdasarkan jarak dan nilai keanggotaan dalam kelompok, menggunakan rumus 4 :

$$
J=\sum \underset{i=1}{n} \quad \sum{ }_{i=1}^{k} a_{i c^{D(x i, c 1)^{2}}}
$$

$\mathrm{n}$ adalah jumlah data, $\mathrm{k}$ adalah jumlah kelompok, ai1 adalah nilaikeanggotaan titik data xi ke kelompokcl yang diikuti. a mempunyai nilai 0 atau 1. Apabila data merupakan anggota suatu kelompok, nilai ai $1=1$. Jika tidak, nilai ai $1=0$. Jika tidak, nilai ai $1=0$.

6. Kembali ke langkah 3, jika masih ada data yang berpindah kelompok, ada perubahan nilai centroid yang telah ditentukan, atau apabila perubahan nilai pada fungsi objektif yang digunakan masih di atas nilai ambang yang ditentukan.

\section{METODE YANG DIUSULKAN}

Penelitian in menggunakan dataset ekspor buahbuahan berdasarkan negara tujuan. Dataset tersebut kemudian dikelompokkan menggunakan algoritma KMeans.

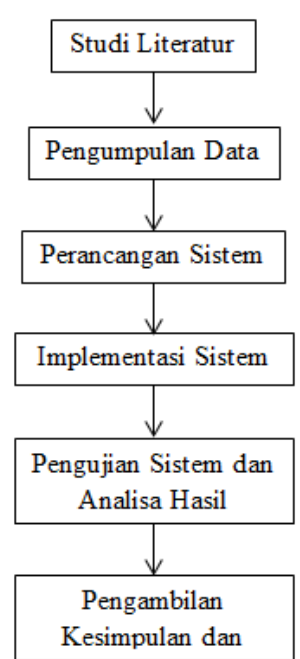

Gambar 3.1. Alur Penelitian

Pengelompokkan data eskpor buah-buahan dengan menggunakan algoritma K-Means ini dilakukan dengan beberapa tahapan, yaitu :

\subsection{Tahap Pengumpulan data}

Dalam penerapan data mining produksi ekspor buah buahan menurut negara tujuan, diperlukan data terkait tentang hal itu. Sumber data penelitian diperoleh dari data yang dikumpulkan berdasarkan dokumendokumen keterangan ekspor impor yang dihasilkan oleh Direktorat Jenderal Bea dan Cukai melalui situs https://www.bps.go.id. Selain itu sejak tahun 2015 data ekspor juga berasal dari PT. Pos Indonesia, catatan instansi lain di perbatasan, dan hasil survei perdagangan lintas batas laut. Data yang digunakan dalam penelitian ini adalah data Ekspor Buah-buahan Menurut Negara Tujuan Utama dari tahun 2012-2019 yang terdiri dari 10 negara yakni Malaysia, Vietnam, Tiongkok, Thailand, India, Jepang, Hongkong, Uni Emirat Arab, Singapura dan Nigeria. Variabel yang digunakan adalah jumlah ekspor berat bersih (netto) dan nilai Free On Board (FOB). Data akan diolah dengan melakukan clustering ekspor buah-buahan berdasarkan negara tujuan utama dalam 3 cluster yakni cluster tingkat ekspor tinggi, cluster tingkat ekspor sedang dan cluster tingkat ekspor rendah.

\subsection{Tahap Pengolahan Data Menggunakan Microsoft Excel}

Tahapan ini merupakan tahapan pengolahan data menggunakan algoritma K-Means untuk mendapatkan kelompok data ekspor buah-buahan berdasarkan negara tujuan. Data yang telah diperolah akan diolah terlebih dahulu untuk dapat dikluster. Dalam tahap sebelumnya, data setiap negara tujuan ekspor buah buahan akan dijumlah setiap aspeknya sehingga pada tahapan ini sudah diperoleh perhitungan nilai yang akan diproses pada tahap clustering. 
Jurnal Ilmiah Ilmu Komputer Vol. 7, No. 2, September 2021

Fakultas Ilmu Komputer

Universitas AL Asyariah Mandar

\subsection{Tahap Implementasi K-Means Cluster Dengan Rapid} Miner

Sebagai bahan perbandingan pengolahan data yang sudah dilakukan menggunakan Microsoft Excel juga dilakukan pengolahan data kembali menggunakan aplikasi Rapminer Studio. Clustering merupakan klasifikasi tanpa pengawasan dan merupakan proses partisi sekumpulan objek data dari satu set menjadi beberapa kelas. Hal ini dapat dilakukan dengan menerapkan berbagai persamaan dan langkah-langkah mengenai jarak algoritma, yaitu dengan Euclidean Distance. Analisis kluster ialah metode yang dipakai untuk membagi rangkaian data menjadi beberapa grup berdasarkan kesamaan-kesamaan yang telah ditentukan sebelumnya. Dalam menentukan cluster berdasarkan data yang telah tersedia, dibutuhkan sebuah flowchart untuk memudahkan dalam menentukan alur perhitungan sebagai alur untuk menemukan hasil dari penerapan cluster terhadap data yang akan diproses.

\subsection{Tahap Analisis Data}

Pada tahapan ini dilakukan analisis data ekspor buah buahan menurut negara tujuan aplikasi tool. Rapid Minner. RapidMiner adalah sebuah lingkungan machine learning data mining, text mining dan predictive analytics [8]. Data yang diperoleh diolah dengan menggunakan perhitungan bobot dari tiap indeks. Pada tahapan sebelumnya, telah ditentukan akan dicluster ke dalam 3 cluster yakni cluster tingkat ekspor tinggi, cluster tingkat ekspor sedang dan cluster tingkat ekspor rendah. Pada tahapan inilah akan dianalisis hasilnya.

\section{HASIL PENELITIAN}

Dalam melakukan clustering, data yang diperoleh akan dihitung terlebih dahulu berdasarkan jumlah ekspor buah buahan pada tahun 2012-2019 berdasarkan negara tujuan. Hasil penjumlahan berdasarkan 2 kriteria penilaian yakni berat bersih (netto) dan nilai FOB seperti yang ditunjukkan pada gambar 4.1

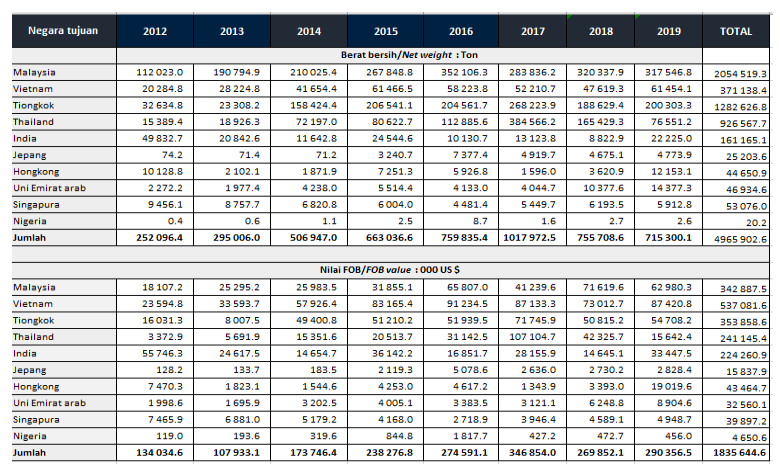

Gambar 4.1 Data ekspor buah-buahan tahun 20122019

Selanjutnya, tahap pertama dalam proses pengolahan data yaitu mengakumulasikan nilai yang
(P) ISSN 2442-451X

(O) ISSN 2503-3832

diambil dari data ekspor buah-buahan berdasarkan negara tujuan yang dapat dilihat pada tabel 4.1.

Tabel 4.1 Data Akumulasi Ekspor Buah-buahan

\begin{tabular}{c|l|c|c}
\hline NO & Negara Tujuan & Netto (TON) & $\begin{array}{c}\text { Nilai FOB (Ribu } \\
\text { US\$) }\end{array}$ \\
\hline 1 & Hongkong & 44650,9 & 43464,7 \\
\hline 2 & Tiongkok & 1282626,8 & 353858,6 \\
\hline 3 & Singapura & 53076 & 39897,2 \\
\hline 4 & Malaysia & 2054519,3 & 342887,5 \\
\hline 5 & Nigeria & 20,2 & 4650,6 \\
\hline 6 & Vietnam & 371138,4 & 531081,6 \\
\hline 7 & India & 16165,1 & 224260,9 \\
\hline 8 & Thailand & 926567,7 & 241145,4 \\
\hline 9 & Jepang & 25203,6 & 15837,9 \\
\hline 10 & Uni Emirat Arab & 46924,6 & 32560,1 \\
\hline
\end{tabular}

\subsection{Input Data}

Data yang digunakan pada penelitian ini adalah data ekspor buah-buahan berdasarkakn negara tujuan. Data in diperoleh dari data yang dikumpulkan berdasarkan dokumen-dokumen keterangan ekspor impor yang dihasilkan oleh Direktorat Jenderal Bea dan Cukai melalui situs https://www.bps.go.id. Data yang telah diakumulasikan akan dimasukan ke dalam tool Rapid Minner. Sehingga dapat diclustering menjadi dua. Setelah dimasukan ke dalam Rapid Minner.

\subsection{Centroid Data}

Dalam penerapan algoritma $k$-means dihasilkan nilai titik tengah atau centroid dari data yang didapat dengan ketentuan bahwa clusterisasi yang diinginkan adalah 3, penentuan cluster dibagi atas tiga bagian yakni cluster tingkat ekspor tinggi (C1), clusteri tingkat ekspor sedang (C2), dan cluster tingkat ekspor rendah (C3). Maka nilai titik tengah atau centroid juga terdapat 3 titik. Penentuan titik cluster ini dilakukan dengan mengambil nilai terbesar (maximum) untuk cluster tingkat ekspor tinggi $(\mathrm{C} 1)$, nilai rata-rata (average) untuk cluster tingkat ekspor sedang (C2), dan nilai terkecil (minimum) untuk cluster tingkat ekspor rendah (C3). Nilai titik tersebut dapat diketahui pada tabel 4.2

- Iterasi Pertama

Tabel 4.2 Centroid Data Iterasi 1

\begin{tabular}{l|llllll}
\hline Atribut & \multicolumn{2}{c}{$\begin{array}{c}\text { Cluster 1 } \\
\text { (Tinggi) }\end{array}$} & \multicolumn{2}{c}{$\begin{array}{c}\text { Cluster 2 } \\
\text { (Sedang) }\end{array}$} & \multicolumn{2}{c}{$\begin{array}{c}\text { Cluster 3 } \\
\text { (Rendah) }\end{array}$} \\
\hline \multirow{2}{*}{ Nilai } & Netto & FOB & Netto & FOB & Netto & FOB \\
& & & & & & \\
\cline { 2 - 7 } & 2054519 & 5370 & 482090. & 1835 & 20.2 & 465 \\
& .3 & 81.6 & 3 & 64.5 & & 0.6 \\
\hline
\end{tabular}

\subsection{Clustering Data}


Jurnal Ilmiah Ilmu Komputer Vol. 7, No. 2, September 2021

Fakultas Ilmu Komputer

Universitas AL Asyariah Mandar

Dengan menggunakan centroid tersebut maka dapat dilakukan proses clustering data yang telah didapat menjadi 3 cluster. Proses cluster dengan mengambil jarak terdekat dari setiap data yang diolah. Proses pencarian jarak terpendek, pengelompokkan data pada iterasi 1 dan clustering data dapat digambarkan pada gambar 4.2.

- Menghitung jarak setiap data ke pusat cluster Jarak setiap data ke pusat cluster ditentukan dengan rumus Euclidian Distance.

\begin{tabular}{|c|c|c|c|c|c|c|c|}
\hline NO & \begin{tabular}{|l|} 
Negara Tujuan \\
\end{tabular} & Netto (TON) & Nilai FOB (Ribu USS) & $\mathrm{C} 1$ & $\mathrm{C2}$ & C3 & Jarak Terpendek \\
\hline 1 & Hongkong & 44650.9 & 43464.7 & 2069596 & \begin{tabular}{|l|l|}
459326.8 \\
\end{tabular} & 59147.6 & 59147.6 \\
\hline 2 & Tiongkok & 1282626.8 & 353858.6 & 793340.2 & 818449.1 & 1329295.3 & 793340.2 \\
\hline 3 & Singapura & 53076 & 39897.2 & 2062272 & $\begin{array}{l}452430.7 \\
\end{array}$ & 63696.5 & 63696.5 \\
\hline 4 & Malaysia & 2054519.3 & 342887.5 & 194194.1 & 1580480 & 2082155.3 & 194194.1 \\
\hline 5 & Nigeria & 20.2 & 4650.6 & 2122369 & 514200.1 & 0.0 & 0.0 \\
\hline 6 & Vietnam & 371138.4 & 537081.6 & 1683381 & 370519.5 & 649008.1 & 370519.5 \\
\hline 7 & India & 16165.1 & 224260.9 & 2062218 & 467699.1 & 220203.0 & 220203.0 \\
\hline 8 & Thailand & 926567.7 & 241145.4 & 1166127 & 448191.7 & 956253.1 & 448191.7 \\
\hline 9 & Jepang & 25203.6 & 15837.9 & 2095189 & 486700.7 & 27556.5 & 27556.5 \\
\hline 10 & Uni Emirat Arab & 46934.6 & 32560.1 & 2070009 & 460611.3 & 54588.5 & 54588.5 \\
\hline & & & & & & & \\
\hline & cluster 1tinggil) & 2054519.3 & & & & & \\
\hline & cluster 2 (sedang & 482090.3 & 183564.5 L & & & & \\
\hline & cluster 3 (rendah & 20.2 & 4650.6 & & & & \\
\hline
\end{tabular}

Gambar 4.2 Perhitungan Jarak Pusat Cluster Iterasi 1

- Pengelompokkan data kedalam cluster

Data yang mempunyai jarak terdekat akan masuk keadalam cluster tersebut.

\begin{tabular}{|c|l|c|c|r|}
\multicolumn{3}{|c|}{ Pengelompokkan Objek } & \\
\hline NO & Negara Tujuan & Netto (TON) & Nilai FOB (Ribu US\$) & Kelompok \\
\hline 1 & Hongkong & 44650.9 & 43464.7 & 3 \\
\hline 2 & Tiongkok & 1282626.8 & 353858.6 & 1 \\
\hline 3 & Singapura & 53076 & 39897.2 & 3 \\
\hline 4 & Malaysia & 2054519.3 & 342887.5 & 1 \\
\hline 5 & Nigeria & 20.2 & 4650.6 & 3 \\
\hline 6 & Vietnam & 371138.4 & 537081.6 & 2 \\
\hline 7 & India & 16165.1 & 224260.9 & 3 \\
\hline 8 & Thailand & 926567.7 & 241145.4 & 2 \\
\hline 9 & Jepang & 25203.6 & 15837.9 & 3 \\
\hline 10 & Uni Emirat Arab & 46934.6 & 32560.1 & 3 \\
\hline
\end{tabular}

Gambar 4.3 Pengelompokkan Data Iterasi 1

- Iterasi Kedua

Setelah proses iterasi 1 selesai perlu dilakukan kembali proses iterasi sampai menemukan hasil yang sama dengan proses iterasi 1. Pada tahap selanjutnya kembali dilakukan proses mencari nilai titik tengah atau centroid untuk iterasi 2 yang dapat dilihat pada tabel 4.3

Tabel 4.3 Centroid Data Iterasi 2

\begin{tabular}{|c|c|c|c|c|c|c|}
\hline Atribut & $\begin{array}{l}\text { Clust } \\
\text { (Tin }\end{array}$ & & $\begin{array}{l}\text { Clust } \\
\text { (Sed }\end{array}$ & & $\begin{array}{l}\text { Clus } \\
\text { (Ren }\end{array}$ & \\
\hline Nilai & Netto & FOB & Netto & FOB & Netto & FOB \\
\hline
\end{tabular}

(P) ISSN 2442-451X

(O) ISSN 2503-3832

\begin{tabular}{l|llllll}
\hline & 1668573 & 3483 & 648853, & 3891 & 31008,4 & 601 \\
& & 73,1 & 1 & 13,5 & & 11,9 \\
\hline
\end{tabular}

Setelah mendapatkan nilai titik tengah atau centroid, proses sama dilakukan dengan mencari jarak terdekat. Proses pencarian jarak terpendek, pengelompokkan data pada iterasi 2 dapat digambarkan pada gambar 4.4 .

- Mengihitung jarak setiap data ke pusat cluster Jarak setiap data ke pusat cluster ditentukan dengan rumus Euclidian Distance.

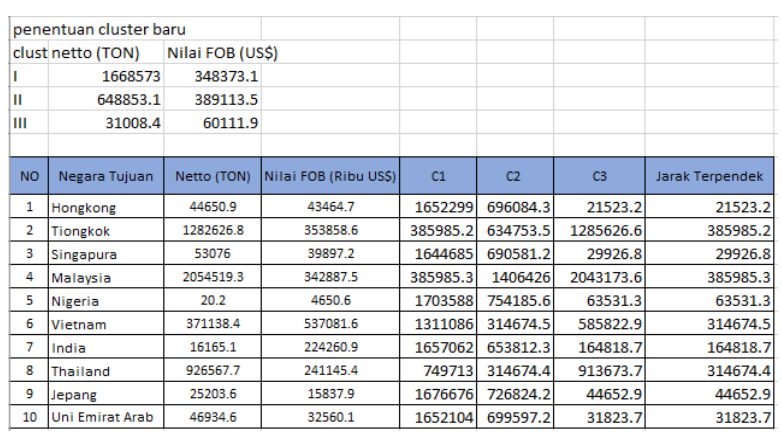

Gambar 4.4 Perhitungan Jarak Pusat Cluster Iterasi 2

- Pengelompokkan data kedalam cluster

Data yang mempunyai jarak terdekat akan masuk keadalam cluster tersebut.

\begin{tabular}{|c|l|c|c|r|}
\hline \multicolumn{6}{|c|}{ Pengelompokkan Objek Baru } \\
\hline No & Negara Tujuan & Netto (TON) & Nilai FOB (Ribu USS) & Kelompok \\
\hline 1 & Hongkong & 44650.9 & 43464.7 & 3 \\
\hline 2 & Tiongkok & 1282626.8 & 353858.6 & 1 \\
\hline 3 & Singapura & 53076 & 39897.2 & 3 \\
\hline 4 & Malaysia & 2054519.3 & 342887.5 & 1 \\
\hline 5 & Nigeria & 20.2 & 4650.6 & 3 \\
\hline 6 & Vietnam & 371138.4 & 537081.6 & 2 \\
\hline 7 & India & 16165.1 & 224260.9 & 3 \\
\hline 8 & Thailand & 926567.7 & 241145.4 & 2 \\
\hline 9 & Jepang & 25203.6 & 15837.9 & 3 \\
\hline 10 & Uni Emirat Arab & 46934.6 & 32560.1 & 3 \\
\hline
\end{tabular}

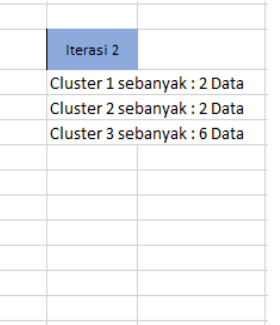

Gambar 4.5 Pengelompokkan Data Iterasi 2

Berdasarkan pengamatan yang telah dilakukan karena hasil dari iterasi 1 dan iterasi 2 sama seperti yang ditunjukan oleh gambar 4.3 dan gambar 4.5, maka tidak perlu dilakukan proses iterasi kembali.

\subsection{Analisa Data}

Pengolahan dataset eksppor buah-buahan berdasarkan negara tujuan telah didapatkan, kemudian akan dilakukan pengolahan dataset kembali menggunakan Rapidminer sebagai bahan perbandingan. Hasil yang didapatkan berdasarkan Rapidminer sebagai berikut : 


\section{Cluster Model}

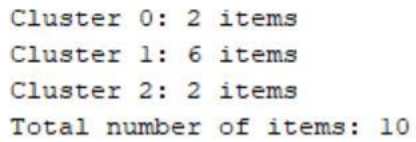

Gambar 4.6 Hasil Cluster Algoritma K-Means

Gambar diatas mengunjukkan hasil dari 10 data ekspor buah-buahan berdasarkan negara tujuan dengan menggunakan algoritma K-Means yang terbagi menjadi 3 cluster yaitu cluster 0 sebanyak 2 negara, cluster 1 sebanyak 6 negara, cluster 2 sebanyak 2 negara.

Clustering data ekspor buah-buahan berdasarkan negara tujuan dengan algoritma K-Means yang menggunakan Microsoft Excel maupun rapidminer menghasilkan pengelompokkan yang sama pada setiap kelompoknya. Berdasarkan hasil pengolahan data didapatkan Cluster tingkat ekspor tinggi (C1) yang mempunyai ekspor buah-buahan tinggi yakni Negara Tiongkok \& Malaysia. Cluster tingkat ekspor sedang (C2) yang mempunyai ekspor buah-buahan sedang yakni Negara Vietnam \& Thailand. Cluster tingkat ekspor rendah (C3) yang mempunyai ekspor buahbuahan rendah yakni Negara Hongkong, Singapura, Nigeria, India, Jepang, Uni Emirat Arab.

Paramater untuk mengukur kinerja algoritma KMeans dilakukan dengan menghitung Davies Bouldin Index dan Avg. Within centroid distance. Davies Bouldin Index merupakan algoritma yang menghasilkan cluster dengan jarak interr-cluster rendah (kesamaan inter-cluster tinggi) dan jarak antar cluster tinggi (kemiripan antar cluster rendah) akan memiliki Davies Bouldin Index yang rendah, algoritma cluster yang menghasilkan kumpulan cluster dengan indeks Davies Bouldin terkecil dianggap sebagai algoritma terbaik berdasarkan kriteria ini. Sedangkan Avg. Within centroid distance merupakan rata-rata dalam jarak cluster dihitung degan rata-rata jarak antara centroid dan semua contoh cluster.

\section{PerformanceVector}

PerformanceVector:

Avg. within centroid distance: 26578804986.110

Avg. within centroid distance_cluster_0: 49509992721.117

Avg. within centroid distance cluster 1: 2963910878.467

Avg. within centroid distance_cluster_2: 74492299574.035 Davies Bouldin: 0.318

Gambar 4.7 Hasil Kinerja

Gambar diatas menunjukkan hasil kinerja dari pengelompokkan data ekspor buah-buahan berdasarkan negara tujuan dengan nilai Davies Bouldin Index sebesar 0.318 dan Avg. Within centroid distance sebesar 26578804986.110 .

Tabel 4.4. Perbandingan Nilai Davies Bouldin Index (DBI)

\begin{tabular}{|c|c|c|c|c|}
\hline K & 2 & 3 & 4 & 5 \\
\hline DBI & 0.219 & 0.318 & 0.113 & 0.034 \\
\hline
\end{tabular}

Tabel diatas menunjukkan perbandingan nilai Davies Bouldin Index berdasarkan jumlah cluster yang ditentukan. Dapat dilihat pada nilai Davies Bouldin Index dengan jumlah cluster 3, nilai yang dihasilkan bukan merupakan yang terbaik. Jumlah cluster terbaik berada pada jumlah K sebanyak 5 dengan nilai Davies Bouldin Index sebesar 0.034.

\section{KESIMPULAN}

Berdasarkan hasil penelitian dan pengamatan yang telah dilakukan Metode Algoritma K-Means Clustering dirasa dapat diterapkan dalam melakukan penilaian terhadap hasil ekspor buah-buahan berdasarkan negara tujuan. Dengan menginput data yang digunakan dalam penelitian ini yaitu data Ekspor Buah-buahan Menurut Negara Tujuan Utama dari tahun 2012-2019 yang diambil dari dokumen-dokumen keterangan ekspor impor yang dihasilkan oleh Direktorat Jenderal Bea dan Cukai.

Penerapan Algoritma K-Means menghasilkan nilai titik tengah atau centroid dari data yang didapat dengan ketentuan bahwa clusterisasi yang diinginkan adalah 3, penentuan cluster dibagi atas tiga bagian yakni cluster tingkat ekspor tinggi (C1), clusteri tingkat ekspor sedang (C2), dan cluster tingkat ekspor rendah (C3). Berdasarkan hasil clusterisasi yang telah dilakukan didapatkan Cluster tingkat ekspor tinggi (C1) yakni Tiongkok \& Malaysia, cluster tingkat ekspor sedang (C2) yakni Vietnam \& Thailand, cluster tingkat ekspor rendah (C3) yakni Hongkong, Singapura, Nigeria, India, Jepang, Uni Emirat Arab.

\section{UCAPAN TERIMA KASIH}

Terima kasih kepada program studi Teknik Informatika, Universitas Singaperbangsa Karawang atas dukungan dalam terlaksanakannya penelitian ini.

\section{Daftar Pustaka}

[1] Y Windarto, A. P. (2017). Penerapan Datamining Pada Ekspor Buah-Buahan Menurut Negara Tujuan Menggunakan K-Means Clustering Method. Techno. Com, 16(4), 348-357.

[2] Anjelita, M., Windarto, A. P., Wanto, A., \& Saifullah, S. (2019, August). Analisis Metode KMeans pada Kasus Ekspor Barang Perhiasan dan Barang Berharga Berdasarkan Negara Tujuan. 
Universitas AL Asyariah Mandar

In Seminar Nasional Sains dan Teknologi Informasi (SENSASI) (Vol. 2, No. 1).

[3] Hajar, S., Novany, A. A., Windarto, A. P., Wanto, A., \& Irawan, E. (2020, February). Penerapan KMeans Clustering Pada Ekspor Minyak Kelapa Sawit Menurut Negara Tujuan. In Seminar Nasional Teknologi Komputer \& Sains (SAINTEKS) (Vol. 1, No. 1, pp. 314-318).

[4] Siyamto, Y. (2017). Pemanfaatan Data Mining Dengan Metode Clustering Untuk Evaluasi Biaya Dokumen Ekspor di PT Winstar Batam. JURNAL MEDIA INFORMATIKA BUDIDARMA, 1(2).

[5] Richel, Y. (2020). PENERAPAN DATA MINING MENGGUNAKAN METODE K-MEANS CLUSTERING PADA DATA EKSPOR MINYAK $P A L A$ (Doctoral dissertation, Universitas Andalas).

[6] Lubis, R. H. (2018). ANALISIS KINERJA EKSPOR-IMPOR BUAH-BUAHAN INDONESIA PADA PERDAGANGAN INTERNASIONAL. Al-Masharif: Jurnal Ilmu Ekonomi dan Keislaman, 6(1), 103-116.

[7] North, M. (2012). Data mining for the masses (Vol. 615684378). Athens: Global Text Project.

[8] Hofmann, M., \& Klinkenberg, R. (Eds.). (2016). RapidMiner: Data mining use cases and business analytics applications. CRC Press.

[9] Darmawan, A., Kustian , N., Rahayu, W., \& Tabebuya. (2018). IMPLEMENTASI DATA MINING MENGGUNAKAN MODEL SVM, 2(3), 299-307. 